\title{
Faktor-faktor yang Mempengaruhi Rendahnya Pelaporan Insiden di Instalasi Farmasi RSUD Ngudi Waluyo Wlingi
}

\section{Factors Affecting Low Incident Reporting at Pharmacy Installation of Ngudi Waluyo Hospital Wlingi}

\author{
Marlina Adrini $T^{1}$, Tuti Harijanto ${ }^{1}$, Endah Woro $U^{2}$ \\ ${ }^{1}$ Program Studi Magister Manajemen Rumah Sakit Fakultas Kedokteran Universitas Brawijaya Malang \\ ${ }^{2}$ Rumah Sakit Umum Daerah Ngudi Waluyo Wlingi
}

\begin{abstract}
ABSTRAK
Keselamatan pasien merupakan bagian penting dalam meningkatkan mutu pelayanan rumah sakit. Salah satu dari tujuh langkah menuju keselamatan pasien adalah mengembangkan Sistim Pelaporan. Berdasarkan hasil pelaporan IKP di RSUD Ngudi Waluyo Wlingi selama periode Desember 2013-Agustus 2014 , laporanan dari Instalasi Farmasi hanya ada 2 (dua). Hal ini menimbulkan kekuatiran bahwa rendahnya pelaporan insiden di Instalasi Farmasi dikarenakan banyak kejadian/insiden yang tidak dilaporkan. Tujuan dari penelitian ini adalah untuk mengidentifikasi, menganalisis dan menentukan faktor-faktor yang mempengaruhi rendahnya pelaporan insiden di Instalasi Farmasi RSUD Ngudi Waluyo Wlingi. Penelitian ini menggunakan metode brainstroming dan Focus Group Discussion dengan petugas farmasi dan jajaran manajemen terkait. Hasil pengamatan dan pencatatan menunjukkan 40 KNC dengan $50 \%$ terjadi pada tahap prescribing, 37,5\% tahap transcribing, dan $12,5 \%$ pada tahap dispensing sedangkan pada tahap administration tidak ditemukan KNC. Menurut hasil analisa faktor yang mempengaruhi pelaporan insiden adalah pengetahuan petugas farmasi kurang tentang apa yang harus dilaporkan dan bagaimana pelaporannya. Formulir untuk pelaporan KNC/KPCyang sederhana dan sistematis juga belum ada. Sebagai solusinya diperlukan pelatihan pelaporan insiden kepada seluruh petugas farmasi. Selanjutnya dibutuhkan komitmen dari pihak direksi, manajemen dan tim KPRS untuk melakukan monitoring dan evaluasi tentang pelaporan IKP dengan cara visitasi secara periodik dan melalui rapat bulanan. Hasil menunjukkan 40 KNC dengan 50\% terjadi pada tahap prescribing, 37,5\% tahap transcribing, dan $12,5 \%$ pada tahap dispensing sedangkan pada tahap administration tidak ditemukan KNC.
\end{abstract}

Kata Kunci: Instalasi farmasi, Keselamatan Pasien Rumah Sakit (KPRS), Pelaporan Insiden Keselamatan Pasien (IKP)

\begin{abstract}
Patient safety is an important aspect in improving the quality of hospital services. One of the seven steps towards patient safety is to develop reporting system. Based on the results of IKP reporting in Ngudi Waluyo Hospital from December 2013 until August 2014, the Pharmacy only reported 2 (two) incidents. The concern rose when the fact was that many events were not reported. The purpose of this study is to identify, analyze, and determine the factors that affect low incident reporting at Pharmacy Installation. This research used brainstorming and focus group discussion methods with pharmacists and related management teams. The results show 40 near miss incidents with $50 \%$ occurred at the stage of prescribing, 37,5\% at transcribing stage, and 12,5\% at the dispensing stage while at the administration stage near miss incident was not found. The factor analysis result shows that pharmacy personnel lack knowledge on what and how to report. Simple and systematic KNC/KPC form has not been yet made as well. The solution of the problem is providing training to all pharmacy personnel. Furthermore, it requires commitment of the board of directors, management, and hospital patient safety team for monitoring and evaluating PSI reporting by performing periodic visits and conducting monthly meetings. The results show 40 near miss incidents with 50\% occurred at the stage of prescribing, 37,5\% at transcribing stage, and 12,5\% at the dispensing stage while at the administration stage near miss incident was not found.
\end{abstract}

Keywords: Patient Safety Incident reporting, Hospital Patient Safety Team, pharmacy installation

Jurnal Kedokteran Brawijaya, Vol. 28, Suplemen No. 2, 2015; Korespondensi: Marlina Adrini T. Program Studi Magister Manajemen Rumah Sakit Fakultas Kedokteran Universitas Brawijaya Malang, Jl. Veteran Malang 65145 Tel. (0341) 569117 Email: m_adrini@yahoo.com 


\section{PENDAHULUAN}

Saat ini Keselamatan Pasien (Patient Safety) menjadi isu penting dalam pelayanan kesehatan. Sejak berlakunya UU No. 8 Tahun 1999 tentang Perlindungan Konsumen dan UU No. 29 Tahun 2004 tentang Praktik Kedokteran, timbul berbagai tuntutan hukum kepada dokter dan Rumah Sakit. Oleh karena itu rumah sakit harus selalu memperhatikan mutu dan keselamatan pasien dalam pelayanannya.

Di Indonesia berdasarkan laporan Peta Nasional Insiden Keselamatan Pasien menyatakan kesalahan pengobatan menduduki peringkat pertama (24,8\%) dari 10 besar insiden yang dilaporkan (1). Kesalahan pengobatan merupakan salah satu indikator tingkat pencapaian keselamatan pasien. Angka kesalahan pengobatan yang terjadi pada pasien yang dirawat di rumah sakit berkisar antara $4 \%-17 \%$. Hal tersebut sangat berpengaruh terhadap mutu pelayanan dan biaya perawatan pasien (2). Penelitian Dwiprahasto melaporkan bahwa $11 \%$ kesalahan pengobatan di rumah sakit berkaitan dengan kesalahan saat menyerahkan obat ke pasien dalam bentuk dosis atau obat yang keliru (3). Tahap pelayanan farmasi yang sering terjadi kesalahan yaitu kesalahan peresepan (54\%) dan kesalahan pemberian dan penggunaan obat (46\%) (4).

Kejadian tidak diharapkan (KTD) yang terjadi di rumah sakit ibarat fenomena gunung es. Artinya yang terdeteksi hanya sebagian kecil KTD saja, sedangkan sebagian besar kejadian cenderung tidak dicatat atau tidak dilaporkan, bahkan luput dari perhatian. Hal ini didukung kajian National Patient Safety Agency (NPSA) yang menafsirkan bahwa jika ada 1 (satu) kejadian KTD berat berarti telah terjadi 25 KTD ringan dan 300 Kejadian nyaris cidera (KNC) yang harus menjadi perhatian (5). Kejadian nyaris cidera dapat terjadi pada $2,5 \%-8 \%$ dari jumlah pasien yang masuk rumah sakit. Hal ini menyebabkan identifikasi kejadian nyaris cidera perlu dilakukan. Akan tetapi kenyataannya banyak kejadian nyaris cidera yang tidak dilaporkan karena pasien belum terpapar/tidak cidera.

Sistim pelaporan kejadian nyaris cidera merupakan upaya yang paling mudah dilakukan (6). Upaya tersebut adalah dengan memunculkan kesalahan agar dapat dilihat dan dipelajari. Hasil pembelajaran dari kesalahan akan mencegah/mengurangi efek yang terjadi, hal ini dapat dilakukan dengan sistem pelaporan (7). Menurut hasil pelaporan IKP di RSUD Ngudi Waluyo Wlingi hanya ada 6 (enam) insiden selama 9 bulan, sedangkan laporan dari Instalasi Farmasi hanya ada 2 (dua) laporan selama periode tersebut. Bila dibandingkan dengan besarnya kunjungan pada rumah sakit, angka tersebut jauh lebih rendah dari prediksi KTD. Kondisi tersebut mengindikasikan bahwa rendahnya pelaporan insiden di Instalasi Farmasi dikarenakan banyak kejadian/insiden yang tidak dilaporkan (8).

Carroll melaporkan bahwa persepsi petugas yang keliru dalam pelaporan kejadian nyaris cidera (KNC) menghambat tindakan pelaporan insiden. Persepsi petugas dipengaruhi oleh pengetahuan tentang apa dan bagaimana cara melapor, sikap skeptis bahwa kalau melapor juga tidak akan terjadi perubahan, keinginan untuk melupakan kejadian, ketakutan akan hukuman, stress serta kurang fokus terhadap kejadian (7).
Berdasarkan penelitian Tamuz et al diperoleh fakta bahwa faktor yang berkontribusi terhadap rendahnya pelaporan insiden adalah persepsi di unit kerja, perasaan takut disalahkan dan kesibukan (9).

Penelitian ini bertujuan untuk mengidentifikasi faktorfaktor yang menghambat pelaporan insiden di Instalasi Farmasi. Selanjutnya akan dianalisa akar masalahyang menghambat pelaporan insiden tersebut, sehingga dapat ditentukan solusinya. Diharapkan dengan penelitian ini, pelaporan insiden sebagai langkah awal untuk membangun budaya keselamatan pasien di rumah sakit akan terwujud.

\section{METODE}

Penelitian dilakukan di Instalasi Farmasi RSUD Ngudi Waluyo Wlingi sejak bulan September sampai Oktober 2014. Pengumpulan data dilakukan dengan teknik wawancara dan observasi. Wawancara dilakukan terhadap 2 tenaga teknis kefarmasian dan 2 tenaga apoteker. Tujuan wawancara untuk mengumpulkan informasi mengenai pelaporan insiden di depo rawat jalan maupun di rawat inap. Observasi dilakukan selama 3 hari dengan mengamati proses kegiatan pelayanan yang dilakukan petugas farmasi di depo rawat jalan. Metode pencatatan membantu pengamatan prosedur pelayanan resep, sejak resep diterima sampai obat diberikan kepada pasien. Pengumpulan data sekunder dilakukan dengan menelaah Laporan Tahunan Standar Pelayanan Minimal (SPM) Rumah Sakit yaitu dokumen Laporan Insiden Keselamatan Pasien periode Desember 2013-Agustus 2014.

Untuk melengkapi data-data disebut diatas, penulis juga melakukan studi pendahuluan untuk melihat gambaran kejadian nyaris cidera/kejadian potensi cidera (KNC/KPC) didalam alur pelayanan farmasi yang seharusnya dilaporkan petugas. Sampel penelitian ini adalah resep. Studi pendahuluan dilakukan di depo rawat jalan dari tanggal 4 Oktober-11 Oktober 2014. Pemilihan depo rawat jalan dengan pertimbangan apabila terjadi kesalahan pengobatan pada pasien tidak dapat langsung ditangani petugas kesehatan. Kesalahan pengobatan dirawat jalan dapat terjadi pada 4 fase yaitu: kesalahan peresepan (Prescribing error), kesalahan menerjemahkan resep (Transcribing error), kesalahan menyiapkan dan meracik obat (Dispensing error) serta kesalahan penyerahan obat kepada pasien (Administration error). Apoteker yang ditunjuk akan menelaah dan mencatat jumlah kesalahan pengobatan yang terjadi pada setiap tahap dalam daftar tilik harian (Lampiran).

Kriteria untuk menentukan frekuensi dan persentase kesalahan pengobatan pada setiap fase sangat bervariasi diantara peneliti tergantung definisi, metodologi dan tujuan penelitian dilakukan. Kriteria yang digunakan pada penelitian ini adalah kriteria yang digunakan pada penelitian Simamora et al dan Perwitasari et al. Simamora et al membagi prescribing error menjadi bentuk sediaan, signa, obat tidak ditulis di catatan medik, kekuatan obat, identitas dan double prescribing. Transcribing error meliputi kesalahan nama obat, jumlah obat, signa dan identitas pasien. Administration error meliputi kesalahan interval pemberian, signa, salah obat, obat tidak diberikan. Penelitian Perwitasari et al membagi dispensing error menjadi tahap penyiapan obat tidak baik dan pemberian 
informasi tidak lengkap.

Penelitian ini juga menggunakan metode curah pendapat dan diskusi kelompok terarah (Focus Group Discussion). Metode curah pendapat dilakukan saat melakukan wawancara dengan para apoteker dan petugas farmasi. Tujuan curah pendapat untuk identifikasi penyebab masalah rendahnya pelaporan insiden di Instalasi Farmasi. Setelah data-data lengkap terkumpul maka pada tanggal 21 Oktober 2014 dilakukan diskusi terarah. Diskusi dihadiri 10 (sepuluh) peserta, yaitu: Wakil Direktur Pelayanan, Ketua Bidang Pelayanan Keperawatan, Ketua Bidang Pelayanan penunjang, Seksi Peningkatan Mutu, Tim KPRS-RS dan Kepala Instalasi Farmasi. Moderator memimpin jalannya diskusi dengan fokus mengindentifikasi akar masalah penghambat pelaporan insiden di Instalasi Farmasi. Tujuan diskusi ini untuk menentukan prioritas akar masalah dengan menggunakan metode USG (Urgency, Seriousness, Growth) dengan skala 1-5. Sesudah didapat prioritas akar masalah yang terpilih, selanjutnya ditentukan alternatif pemecahan masalah dengan menggunakan tapisan Mc. Namara. Teori tapisan Mc Namara akan menentukan 3 (tiga) kriteria yang dinilai dari setiap alternatif pemcahan masalah yaitu efektivitas, efisiensi (biaya), dan kemudahan pemecahan masalah tersebut dilakukan. Perlu dipertimbangkan berbagai hal diantaranya pertama adalah efektivitas apabila dapat berhasil guna, berdaya guna dan memberikan nilai tambah bagi organisasi. Aspek kedua adalah efisiensi (biaya). Alternatif solusi yang biayanya rendah makin baik bagi pelaksanaanya. Aspek ketiga adalah kemudahan pelaksanaan pemecahan masalah diimplementasikan. Tiap kriteria diberikan skor nilai antara 1-5, dari skor 1 tidak penting sampai skor 5 paling penting. Total skor tertinggi adalah prioritas pemecahan masalah yang dipilih manajemen untuk segera diimplementasikan.

\section{HASIL}

\section{Gambaran Kejadian Nyaris Cidera di Depo Rawat Jalan}

Pada setiap proses pelayanan mungkin saja terjadi kejadian tidak dikehendaki (KTD), kejadian nyaris cidera (KNC) maupun kejadian potensi cidera (KPC). Akan tetapi selama proses pengamatan di depo rawat jalan kami tidak menemukan insiden kesalahan pengobatan yang mengancam jiwa pasien/terpapar kepada pasien. Tujuan pengamatan dan pencatatan dilakukan untuk memberi gambaran berapa banyak kejadian nyaris cidera/potensi cidera yang seharusnya dilaporkan.

Tabel 1 menunjukkan hasil pencatatan 40 kejadian nyaris cidera pada tahap prescribing ada 20 kejadian (50\%), transcribing ada 15 kejadian (37,5\%), tahap dispensing ada 5 kejadian (12,5\%) dan pada tahap Administration tidak ada kejadian (0\%). Hal ini menunjukkan bahwa sebenarnya cukup banyak kejadian nyaris cidera di depo rawat jalan yang tidak dicatat dan tidak dilaporkan. Jenis kejadian nyaris cidera pada setiap setiap tahapan yang ditemukan oleh apoteker yang ditunjuk dan dilaporkan petugas farmasi juga disajikan pada Tabel 1. Pada tahap prescribing kesalahan terbesar adalah pencantuman kekuatan dan signa, pada transcribing adalah dosis, dan pada dispensing adalah penyiapan obat, sedangkan pada tahap administration tidak ditemukan kesalahan selama pengamatan.
Tabel 1. Frekuensi dan persentase KNC tiap fase pelayanan

\begin{tabular}{ccc}
\hline Tipe Kejadian Nyaris Cidera & Frekuensi & ( \% ) \\
\hline Prescribing error & & 50 \\
$\square \quad$ Identitas pasien & 4 & 16 \\
$\square \quad$ Kekuatan obat & 8 & 32 \\
$\quad$ Signa & 8 & 32 \\
Transcribing error & & 37,5 \\
$\square \quad$ Nama obat & 5 & 20 \\
$\square \quad$ Dosis & 6 & 24 \\
$\square \quad$ Jumlah obat & 4 & 16 \\
Dispensing error & & 12,5 \\
$\square \quad$ Penyiapan obat & 4 & 16 \\
Informasi obat & 1 & 4 \\
TOTAListration error & 0 & 0 \\
&
\end{tabular}

\section{Identifikasi Penyebab Masalah}

Identifikasi akar penyebab penyebab masalah berdasarkan wawancara dan diskusi dikelompokkan menjadi empat faktor yaitu petugas, metode, materi dan sistem. Pada faktor petugas, petugas farmasi mengetahui bahwa jika ada insiden yang terpapar ke pasien harus segera melapor ke Kepala Instalasi Farmasi. Akan tetapi mereka tidak paham jika kejadian yang berpotensi cidera juga penting dilaporkan, walaupun pasien belum terpapar. Ini terlihat dari jawaban petugas "Perawat sudah memberitahu kami jika salah obatnya, kemudian kami ganti. Lagipula obat juga belum diberikan kepada pasien, berarti tidak perlu dilaporkan. Kecuali obat sudah terlanjur diberikan kepada pasien itu memang harus dilaporkan". Asisten apoteker banyak yang belum paham kejadian apa saja yang tergolong nyaris cidera atau potensi cidera. Disamping pemahaman, beban kerja juga dapat menjadi penyebab masalah. Beban kerja petugas yang tinggi dalam pelayanan farmasi sering menyebabkan kelelahan dan ketergesagesaan. Hal ini menyebabkan petugas mengabaikan pencatatan dan pelaporan. Ini terlihat dari jawaban petugas "Disini kami kekurangan tenaga, mengerjakan resep saja sudah sibuk apalagi ditambahi pekerjaan mencatat". Penumpukan resep di depo rawat jalan tidak dapat dihindari walaupun loket pendaftaran sudah ditutup. Hal ini disebabkan resep datang bersamaan sehingga semua resep tuntas terlayani hingga sore hari.

Faktor metode dapat mempengaruhi proses pelaporan KNC. Kejadian nyaris cidera juga berpotensi menyebabkan cidera yang perlu didukung dengan prosedur pelaporan yang jelas. Petugas farmasi menyatakan tidak mengetahui jika ada Standar Operasional Prosedur (SOP) untuk pelaporan KNC yang tampak dari respon berikut: "Saya tidak tahu kalau kejadian belum sampai ke pasien juga harus dilaporkan. Apa ada SOP nya? Saya tidak pernah tahu". Monitoring dan evaluasi dilakukan tim KPRS hanya pada kejadian/insiden yang sudah terpapar pada pasien. Monitoring dan evaluasi terhadap investigasi sederhana yang dilakukan di instalasi tidak pernah dilakukan. Petugas mengatakan "Setiap senin pagi kami ada rapat untuk membahas semua hal termasuk jika ada laporan kesalahan dalam pengobatan. Tetapi setahu saya belum pernah dihadiri pihak manajemen". Monitoring dan evaluasi dengan memberi umpan balik penting dilakukan manajemen agar memberi semangat bagi petugas pelayanan dan proses pembelajaran untuk pencegahan 
tercapai.

Dalam proses pelaporan, ketersediaan dan kesesuaian formulir merupakan salah satu bahan penting. Formulir pelaporan insiden yang tersedia berupa 3 halaman yang perlu dilengkapi untuk pelaporan ke tim Keselamatan Pasien Rumah Sakit (KPRS). Melengkapi pelaporan tentu saja membutuhkan waktu lebih banyak. Petugas mengatakan "Formulir itu untuk kejadian yang sudah mengenai pasien. Apa kalau kejadiannya sudah berhasil kami intervensi juga harus melengkapi formulir yang 3 halaman itu. Kalau begitu jam berapa baru bisa kami selesai". Kejadian nyaris cidera tentu lebih banyak terjadi. Hal ini menyebabkan pengisian formulir yang terlalu banyak akan menimbulkan kemalasan/keengganan petugas mencatat karena menyita waktu.

Secara sistem, wawancara menunjukkan bahwa petugas farmasi belum pernah mendapatkan pelatihan pelaporan insiden. Petugas mengatakan "Wajar jika kami tidak tahu kalau ibu tanya apa itu kejadian nyaris cidera. Bagaimana dan kemana kami harus melaporkan. Selama saya bekerja rasanya belum pernah ikut pelatihan".

\section{Identifikasi Akar Masalah}

Hasil diskusi kelompok terarah dengan pihak manajemen untuk identifikasi akar masalah dengan menggunakan diagram why (Tabel 2). Hasil diskusi didapatkan 5 akar masalah dari rendahnya pelaporan insiden di Instalasi farmasi sebagai berikut: 1) Sosialisasi pelaporan Insiden Keselamatan Pasien (IKP) kurang, 2) Kebijakan penambahan tenaga farmasi, 3) Formulir tidak sistimatis dan sederhana, 4) SOP untuk pelaporan KNC tidak ada, 5) Pelatihan pelaporan insiden belum pernah dilakukan.

Dari hasil analisa USG ditetapkan prioritas akar masalah yang dipilih (ranking I) adalah sosialisasi pelaporan IKP belum dilakukan. Proses FGD mengidentifikasi lima alternatif penyelesaian masalah yang kemudian dilakukan pemilihan teori tapisan Mc Namara. Hasil penapisan menunjukkan bahwa solusi pelatihan internal dan workshop tentang pelaporan insiden KNC menjadi solusi prioritas (Tabel 3). Hal ini juga ditunjang dengan fakta bahwa hasil pencapaian SPM tahun 2013 pada Program Pelatihan Patient Safety baru mencapai 6,96\%.
Tabel3. Hasil pemilihan prioritas pemecahan masalah

\begin{tabular}{|c|c|c|c|c|c|}
\hline No & $\begin{array}{l}\text { Alternatif pemecahan } \\
\text { masalah }\end{array}$ & Efektifitas & Efisiensi & Kemudahan & Total \\
\hline 1. & $\begin{array}{l}\text { Pelatihan internal dan } \\
\text { workshop tentang } \\
\text { pelaporan insiden. }\end{array}$ & 45 & 40 & 40 & 125 \\
\hline 2. & $\begin{array}{l}\text { Program orientasi untuk } \\
\text { pegawai yang baru } \\
\text { tentang pelaporan. }\end{array}$ & 45 & 25 & 25 & 95 \\
\hline 3 & $\begin{array}{l}\text { Informasi pelaporan } \\
\text { insiden dalam buletin } \\
\text { rumah sakit. }\end{array}$ & 40 & 25 & 25 & 90 \\
\hline 4 & $\begin{array}{l}\text { Komitmen manajemen } \\
\text { dengan visitasi periodik } \\
\text { ke unit dan instalasi. }\end{array}$ & 45 & 45 & 25 & 115 \\
\hline 5 & $\begin{array}{l}\text { Melatih "Champion" } \\
\text { keselamatan pasien di } \\
\text { setiap unit dan instalasi. }\end{array}$ & 45 & 35 & 40 & 120 \\
\hline
\end{tabular}

\section{DISKUSI}

\section{Kejadian Nyaris Cidera di Depo Rawat Jalan}

Penelitian Perwitasari et al di Jogyakarta melaporkan kesalahan peresepan yang paling banyak terjadi yaitu $99,12 \%$ (10). Hal yang sama juga dilaporkan oleh Camire et al bahwa kesalahan peresepan yang paling sering terjadi (54\%). Hasil pengamatan yang kami peroleh juga menunjukkan kesalahan pada tahap prescribing paling besar (50\%). Apabila dilihat dari macam kesalahan, frekuensi dalam hal dosis/kekuatan obat paling tinggi (32\%). Contoh kejadian tersebut misalnya Meloxicam ditulis dosis $10 \mathrm{mg}$ padahal yang tersedia adalah dosis $7,5 \mathrm{mg}$ atau $15 \mathrm{mg}$. Furosemid ditulis $20 \mathrm{mg}$ sedangkan sediaan hanya ada $40 \mathrm{mg}$. Signa dalam resep tidak lengkap juga sering ditemukan (32\%). Hal tersebut memerlukan konfirmasi ulang kepada dokter penulis resep. Menurut keterangan apoteker farmasi yang banyak melakukan kesalahan menulis dosis obat dan menulis signa tidak lengkap itu adalah dokter intership yang sedang magang di rumah sakit, karena RSUD Ngudi Waluyo adalah rumah sakit pendidikan.

Tahap menerjemahkan resep oleh petugas farmasi pada pengamatan kami cukup besar $(37,5 \%)$. Hal ini berbeda dengan penelitian Simamora et al yang menyebutkan

Tabel 2. Identifikasi akar masalah

\begin{tabular}{|c|c|c|c|c|c|}
\hline No. & Faktor & Rumusan Masalah & Why & Why & Why \\
\hline \multirow[t]{2}{*}{1} & Petugas & $\begin{array}{l}\text { Pengetahuan petugas tentang } \\
\text { pelaporan insiden kurang }\end{array}$ & $\begin{array}{l}\text { Petugas tidak paham } \\
\text { hal-hal apa saja yang } \\
\text { dilaporkan }\end{array}$ & $\begin{array}{l}\text { Tidak mendapat } \\
\text { informasi tentang } \\
\text { KTD/KNC/KPC }\end{array}$ & $\begin{array}{l}\text { Sosialisasi tentang } \\
\text { pelaporan IKP belum } \\
\text { dilakukan }\end{array}$ \\
\hline & & Petugas tidak sempat mencatat & Beban kerja tinggi & Petugas farmasi kurang & $\begin{array}{l}\text { Belum ada kebijakan } \\
\text { untuk penambahan } \\
\text { tenaga }\end{array}$ \\
\hline 2 & Material & $\begin{array}{l}\text { Melengkapi formulir pelaporan } \\
\text { menyita waktu }\end{array}$ & $\begin{array}{l}\text { Formulir yang harus diisi } \\
\text { banyak }\end{array}$ & $\begin{array}{l}\text { Formulir tidak sistimatis } \\
\text { dan sederhana }\end{array}$ & \\
\hline \multirow[t]{2}{*}{3} & Metode & Tidak tahu harus melapor KNC & $\begin{array}{l}\text { Tidak ada SOP untuk } \\
\text { pelaporan KNC harian }\end{array}$ & $\begin{array}{l}\text { Belum ada kebijakan } \\
\text { untuk SOP tersebut }\end{array}$ & \\
\hline & & $\begin{array}{l}\text { Monitoring dan evaluasi untuk } \\
\text { KNC tidak dilakukan }\end{array}$ & $\begin{array}{l}\text { Belum menyadari } \\
\text { pentingnya pelaporan }\end{array}$ & $\begin{array}{l}\text { Sosialisasi tentang } \\
\text { pelaporan IKP kurang }\end{array}$ & \\
\hline 4 & Sistem & $\begin{array}{l}\text { Pelatihan belum pernah } \\
\text { dilakukan }\end{array}$ & $\begin{array}{l}\text { Belum ada kebijakan } \\
\text { untuk pelatihan }\end{array}$ & & \\
\hline
\end{tabular}


kesalahan pada tahap menerjemahkan resep sebesar $11,16 \%$. Frekuensi kesalahan pada fase ini paling besar (24\%) adalah menerjemaahkan dosis obat. Misalnya Amlodipine $5 \mathrm{mg}$ dimasukkan datanya $10 \mathrm{mg}$. Proses yang lain adalah menerjemahkan nama obat (20\%) misalnya Nabic dimasukkan Nadic. Kesalahan pada proses menerjemaahkan/membaca resep disebabkan karena petugas tergesa-gesa sehingga tidak teliti. Kesalahan paling banyak ditemukan pada siang hari ketika resep rawat jalan menumpuk dan antrian pasien masih banyak. Kesalahan ini diketahui setelah apoteker peneliti melakukan pemeriksaan ulang resep.

Penelitian Perwitasari et al melaporkan kesalahan pada fase dispensing $3,66 \%$ yang terbanyak tidak lengkap informasi obat (2,18\%). Ada perbedaan dengan hasil pengamatan kami, kesalahan pada fase ini $(12,5 \%)$ dan yang sering terjadi adalah pada tahap penyiapan obat $(16 \%)$. Contohnya pada resep tertulis nama obat Irbesartan $300 \mathrm{mg}$ yang diambil dosis $150 \mathrm{mg}$. Dosis Amlodipine $10 \mathrm{mg}$ yang diambil petugas dosis $5 \mathrm{mg}$. Hal ini disebabkan petugas farmasi kurang konsentrasi dan tidak membaca dosis pada waktu mengambil obat. Kejadian lain pada fase ini adalah obat tidak terlayani/diambilkan, sebab pada waktu menyiapkan obat dipanggil teman sehingga lupa ada obat yang belum diambilkan. Kesalahan ini disadari sendiri oleh petugas yang mengambil obat atau ditemukan petugas yang memberikan etiket obat.

Selama pengamatan kami tidak menemukan kekeliruan penyerahan obat, walaupun menurut keterangan yang diberikan petugas kejadian salah penyerahan obat pernah terjadi. Hal itu disebabkan petugas lupa melakukan identifikasi ulang sebelum obat diserahkan kepada pasien karena tergesa-gesa melihat antrian pasien masih banyak. Pencatatan pemberian obat di depo rawat inap akan memberikan hasil berbeda. Hal ini disebabkan proses pemberian obat diruang rawat inap melibatkan perawat, petugas farmasi maupun keluarga pasien di ruangan. Penelitian Camire et al melaporkan kesalahan yang paling sering terjadi selain peresepan adalah admistration error (46\%) di ruang rawat inap (4). Bahkan menurut penelitian Simamora et al di Rumah Sakit R.K.Charitas Palembang kesalahan pemberian obat di ruang rawat inap sebesar $81,32 \%(11)$.

Hasil evaluasi kesalahan pengobatan diantara para peneliti memberikan hasil yang sangat bervariasi. Hal ini disebabkan perbedaan definisi, terminologi, tujuan dan metode penelitian yang dipakai berbeda satu dengan yang lainnya (4). Hasil pencatatan daftar tilik menunjukkan bahwa sebenarnya banyak kejadian nyaris cidera di depo rawat jalan yang seharusnya dicatat sehingga dapat dilaporkan untuk proses evaluasi. Evaluasi hasil pelaporan bukan untuk mencari siapa yang bersalah, tetapi menelusuri mengapa kesalahan itu dapat terjadi. $\mathrm{Hal}$ ini harus ditekankan kepada petugas pelayanan farmasi sehingga memiliki kesadaran budaya melapor itu penting. Sering kali budaya melapor diabaikan karena alasan kesibukan dan sikap tidak peduli terhadap keselamatan pasien.

Upaya Peningkatan Pelaporan Insiden Keselamatan Pasien, Sosialisasi Prosedur Pelaporan Insiden Keselamatan Pasien

Kegiatan belajar dari pelaporan insiden akan mengawali program keselamatan Rumah Sakit. Program pelaporan insiden keselamatan pasien akan menggerakan proses berikutnya dalam analisa kejadian, identifikasi faktor penyebab, mencari solusi dan implementasi untuk pencegahan (manajemen resiko). Dapat dikatakan bahwa pelaporan insiden dapat digunakan sebagai alat monitor upaya pencegahan kesalahan pengobatan (medictionl error). Selain itu pelaporan penting untuk proses pembelajaran agar kejadian yang sama tidak terulang kembali.

Pelaporan insiden dan proses-proses lanjutannya merupakan jawaban yang tepat untuk kejadian tidak diharapkan (KTD) dan kejadian nyaris cidera (KNC). Diharapkan pada masa yang akan datang jumlah KTD/KNC dapat berkurang dan yang terpenting memberikan asuhan yang lebih aman kepada pasien. Pelaporan insiden ditujukan meningkatkan keselamatan pasien, meningkatkan mutu pelayanan dan tidak menyalahkan petugas (non blaming culture).

Pelaporan insiden keselamatan pasien adalah suatu sistem yang mendokumentasikan laporan insiden keselamatan pasien, analisis dan solusi untuk pembelajaran. Sistim pelaporan akan mengajak semua petugas pelayanan dalam organisasi untuk peduli terhadap bahaya/potensi bahaya yang mungkin terjadi terhadap pasien. Oleh karena itu perlu sosialisasi sistim pelaporan insiden kepada seluruh petugas pada umumnya dan petugas farmasi pada khususnya. Sosialisasi tersebut meliputi kebijakan, alur pelaporan, formulir pelaporan insiden internal dan eksternal maupun prosedur pelaporan.

Menurut Budihardjo penanaman nilai-nilai safety dapat dilakukan pertama kali dengan sosialisasi secara informal maupun formal, misalnya dengan selalu dilakukan penanaman nilai-nilai tersebut melalui cerita. Sosialisasi dapat pula dilakukan melalui walk the talk, atau MBWA (Management by Walking Around); para pemimpin secara berkala mendatangi para stafnya selain mengontrol juga selalu mengingatkan pentingnya keselamatan pasien (12).

Pelatihan Internal dan Workshop Pelaporan Insiden Keselamatan Pasien

Proses pembelajaran keselamatan pasien memang bukan hal yang mudah dan sederhana. Hal ini disepakati manajemen RSUD Ngudi Waluyo Wlingi dengan melakukan pelatihan internal dan workshop tentang pelaporan insiden. Pelatihan dilakukan kepada seluruh petugas farmasi, sebagai awal dari proses pembelajaran ini. Kemudian akan diikuti pelatihan kepada petugas unit dan instalasi lainnya pada kesempatan lainnya. Pelatihan internal dibantu oleh tim KPRS yang sudah mengikuti pelatihan eksternal tentang patient safety. Pelatihan internal tentang insiden keselamatan pasien bertujuan untuk meningkatkan pengetahuan, membangun kesamaan persepsi, dan juga menjadi proses pembelajaran.

Pengetahuan adalah hasil tahu dan terjadi setelah orang melakukan penginderaan terhadap suatu objek tertentu. Penginderaan, penciuman, rasa, dan raba. Pengatahuan atau kognitif merupakan domain yang sangat penting dalam membentuk tindakan seseorang (12). Pengetahuan merupakan produk sistem pendidikan dan dengan pengalaman akan memberikan ketrampilan. Pengetahuan yang diperoleh dari proses belajar dapat ditingkatkan melalui pelatihan (14). Berdasarkan wawancara dengan petugas farmasi, mereka tidak tahu apa saja yang termasuk insiden keselamatan pasien dalam pelayanan farmasi dan harus dilaporkan. Petugas tahu jika terjadi 
insiden yang menciderai pasien harus segera dilaporkan. Akan tetapi mereka tidak tahu bahwa kejadian yang nyaris menciderai ataupun berpotensi menciderai pasien juga harus dilaporkan.

Persepsi didefinisikansebagai suatu proses dimana individu memberi arti terhadap stimuli dari lingkungan berdasarkan kesan yang ditangkap oleh panca inderanya (13). Akibatnya persepsi petugas yang keliru dalam pelaporan kejadian nyaris cidera menghambat tindakan pelaporan insiden (15). Berdasarkan wawancara dengan petugas, beberapa persepsi keliru yang ditemukan dalam hal pelaporan kejadian nyaris cidera misalnya: 1) "Saya sudah memperbaiki resepnya, berarti itu bukan termasuk kesalahan", 2) "Bukan saya yang melakukan, tapi teman saya. Biar dia saja yang melapor", 3) "Itu hanya kesalahan administratif, bukan kesalahan pelayanan" dan 4) "Obatnya belum diberikan ke pasien, jadi bukan termasuk kesalahan".

Pelaporan akan memberikan manfaat bila di respon secara kontruktif. Dalam arti paling tidak ada umpan balik terhadap pelaporan tersebut. Untuk itu diperlukan dukungan dari pihak manajemen dalam hal kebijakan,

\section{DAFTAR PUSTAKA}

1. Direktorat Bina Farmasi Komunitas dan Klinik Ditjen Bina Kefarmasian dan Alat Kesehatan. Tanggung Jawab Apoteker Terhadap Keselamatan Pasien (Patient Safety). Jakarta: Departemen Kesehatan; 2008.

2. da Silva LOG, de Oliveira AIM, de Araujo IB, and Saldanha V. Prescribing Errors in an Intensive Care Unit and the Role of the Pharmacist. Revista Brasileira de Farmácia Hospitalar e Serviços de Saúde. 2012; 3(3): 6-9.

3. Dwiprahasto I. Medical Error di Rumah Sakit dan Upaya untuk Meminimalkan Risiko. Jurnal Manajemen Pelayanan Kesehatan. 2004; 7(01); 1317.

4. Camire E, Moyen E, and Stelfox HT. Medication Errors in Critical Care: Risk Factors, Prevention and Disclosure. Canadian Medical Association Journal. 2009; 180(9): 936-943.

5. Cahyono JBSB. Membangun Budaya Keselamatan Pasien dalam Praktik Kedokteran. Yogjakarta: Kanisius; 2008.

6. Olsen S, Neale G, Schwab K, et al. Hospital Staff Should Use More than One Method to Detect Adverse Events and Potential Adverse Events: Incident Reporting, Pharmacist Surveillance and Local Real-Time Record Review May All Have a Place. Quality and Safety in Health Care. 2007; 16(1): 40-44.

7. Beginta R. Pengaruh Budaya Keselamatan Pasien, Gaya Kepemimpinan, Tim Kerja terhadap Persepsi Pelaporan Kesalahan Pelayanan oleh Perawat di Unit Rawat Inap RSU Daerah Kabupaten Bekasi tahun 2011. [Tesis]. Universitas Indonesia, Jakarta. 2012. monitoring, evaluasi dan penghargaan mengenai pelaporan insiden keselamatan pasien. Hal ini tentu akan memberikan semangat bagi petugas untuk melakukan pelaporan sebagai proses pembelajaran.

Penelitian ini mengidentifikasi besarnya potensi insiden atau kejadian nyaris cedera pada pelayanan farmasi rawat jalan. Beberapa faktor yang menjadi penyebab adalah pemahaman tentang pentingnya pelaporan potensi insiden dan lemahnya implementasi sistem pelaporan insiden dan potensi insiden. Melakukan kesalahan adalah manusiawi (to err is human) tetapi akibat dari kesalahan merugikan orang lain dan kadang berakibat fatal. Untuk mencegah terjadinya atau berulangnya kesalahan pendekatan sistem lebih tepat untuk solusinya. Dalam hal ini manajemen rumah sakit mengupayakan seoptimal mungkin tindakan preventif. Akan tetapi pendekatan sistem kadang tidak berjalan karena faktor manusia serta budaya organisasi yang tidak mendukung. Pelaporan insiden dalam organisasi berkorelasi dengan budaya keselamatan oleh karena itu perlu dilakukan upaya sosialisasi, pelatihan pelaporan dan pembelajaran dari kesalahan/insiden untuk menumbuhkan budaya keselamatan di rumah sakit.

8. RSUD Ngudi Waluyo Wlingi. Pelaporan Insiden Keselamatan Pasien Tim Mutu Penunjang 2014. Blitar: RSUD Ngudi Waluyo; 2014.

9. Tamuz M, Thomas EJ, and Franchois KE. Defining and Classifying Medical Error: Lessons for Patient Safety Reporting Systems. Quality and Safety in Health Care. 2004; 13(1): 13-20.

10. Perwitasari DA, Abror J, and Wayuningsih I. Medication Errors in Outpatients of a Government Hospital in Yogyakarta Indonesia. International Journal of Pharmaceutical Sciences Review and Research. 2010; 1(1): 8-10.

11. Simamora S, Paryanti, dan Mangunsong S. Peran Tenaga Teknis Kefarmasian dalam Menurunkan Angka Kejadian Medication Error. Jurnal Manajemen Pelayanan Kesehatan. 2011; 14(04): 207-212.

12. Budihardjo A. Pentingnya Safety Culture di Rumah Sakit-Upaya Meminimalkan Adverse Events. Jurnal Manajemen Bisnis. 2008; 1(1): 53-70.

13. Murdyastuti S. Pengaruh Persepsi Tentang Profesionalitas, Pengetahuan Patients Safety dan Motivasi Perawat terhadap Pelaksanaan Program Patients Safety di Ruang Rawat Inap RSO Prof. Dr. R. Soeharso Surakarta. [Tesis]. Universitas Sebelas Maret, Surakarta. 2010.

14. Ayudyawardani SD. Pengembangan Model Budaya Keselamatan Pasien yang Sesuai di Rumah Sakit Ibu Anak Tumbuh Kembang Cimanggis tahun 2012. [Tesis]. Universitas Indonesia, Jakarta. 2012.

15. Uribe CL, Schweikhart SB, Pathak DS, Dow M, and Mars GB. Perceived Barriers to Medical-Error Reporting: An Exploratory Investigation. Journal of Healthcare Management. 2002; 47(4): 263-279. 
Formulir Harian Pencatatan KTD/KNC/KPC

\begin{tabular}{|c|c|c|c|c|c|c|c|c|c|c|}
\hline \multirow[b]{2}{*}{$\begin{array}{c}\text { Waktu } \\
\text { Pengamatan }\end{array}$} & \multirow[b]{2}{*}{$\begin{array}{c}\text { No } \\
\text { Subjek }\end{array}$} & \multicolumn{3}{|c|}{ Prescribing } & \multicolumn{3}{|c|}{ Transcribing } & \multicolumn{2}{|c|}{ Dispensing } & \multirow[b]{2}{*}{ Keterangan } \\
\hline & & $\begin{array}{c}\text { Identifikasi } \\
\text { px tidak } \\
\text { lengkap } \\
\end{array}$ & $\begin{array}{l}\text { Dosis } \\
\text { tidak } \\
\text { jelas }\end{array}$ & $\begin{array}{c}\text { Signa } \\
\text { tdk jelas }\end{array}$ & $\begin{array}{l}\text { Dosis } \\
\text { obat }\end{array}$ & $\begin{array}{c}\text { Jumlah } \\
\text { obat }\end{array}$ & $\begin{array}{c}\text { Nama } \\
\text { obat }\end{array}$ & $\begin{array}{c}\text { Penyiapan } \\
\text { obat }\end{array}$ & $\begin{array}{c}\text { Informasi } \\
\text { obat }\end{array}$ & \\
\hline \multirow[t]{10}{*}{1} & 1 & & & $\mathrm{x}$ & & & & & & Signa tidak jelas \\
\hline & 2 & & & $\mathrm{x}$ & & & & & & Signa tidak jelas \\
\hline & 3 & $\mathrm{x}$ & & & & & & & & Tidak tercantum berat badan \\
\hline & 4 & & & & & & & $\mathrm{x}$ & & Betametason salep tidak diambil \\
\hline & 5 & & $\mathrm{x}$ & & & & & & & Dosis tidak tertulis \\
\hline & 6 & $\mathrm{x}$ & & & & & & & & Umur tidak ditulis \\
\hline & 7 & & & $\mathrm{x}$ & & & & & & Signa tidak lengkap \\
\hline & 8 & & & $\mathrm{x}$ & & & & & & Signa tidak lengkap \\
\hline & 9 & & $\mathrm{x}$ & & & & & & & Dosis tidak ditulis \\
\hline & 10 & & & & & $\mathrm{x}$ & & & & Propanolol di masukkan kurang jumlahnya \\
\hline \multirow[t]{2}{*}{ II } & 11 & & & $\mathrm{x}$ & & & & & & Tidak ditulis signanya \\
\hline & 12 & & $\mathrm{x}$ & & & & & & & Dosis tidak ditulis \\
\hline \multirow[t]{9}{*}{ III } & 13 & & & $\mathrm{x}$ & & & & & & Signa tidak lengkap \\
\hline & 14 & & & & $x$ & & & & & Meloxicam 7,5 mg di masukkan 15 mg \\
\hline & 15 & & & & & & & & $\mathrm{x}$ & Salah tertulis di label Siti Munawaroh \\
\hline & 16 & & & & $\mathrm{x}$ & & & & & Amlodipine 5 mg dimasukkan 10 mg \\
\hline & 17 & & & & $x$ & & & & & Salah membaca dosis obat \\
\hline & 18 & & $\mathrm{x}$ & & & & & & & Meloxicam ditulis $10 \mathrm{mg}$ \\
\hline & 19 & & & & & & $\mathrm{x}$ & & & Methylprednison tidak dimasukkan \\
\hline & 20 & & & & & & & $\mathrm{x}$ & & Irbesartan 300 mg diambilkan 150 mg \\
\hline & 21 & & & & $\mathrm{x}$ & & & & & Codein 10 dimasukkan 15 \\
\hline \multirow[t]{3}{*}{ IV } & 22 & & & & & & & $\mathrm{x}$ & & Amoxilin ambil kebanyakan 2 \\
\hline & 23 & & & & & & $\mathrm{x}$ & & & Nabic dimasukkan Nadic \\
\hline & 24 & & & & & $\mathrm{x}$ & & & & Lisino 5 di masukkan 10 \\
\hline \multirow[t]{3}{*}{$\mathrm{v}$} & 25 & & $x$ & & & & & & & Furosemid $40 \mathrm{mg}$ ditulis $20 \mathrm{mg}$ \\
\hline & 26 & $\mathrm{x}$ & & & & & & & & Berat badan tidak ditulis \\
\hline & 27 & & & & & & & $\mathrm{x}$ & & Amlodipine $10 \mathrm{mg}$ diambilkan $5 \mathrm{mg}$ \\
\hline \multirow[t]{6}{*}{$\mathrm{VI}$} & 28 & $\mathrm{x}$ & & & & & & & & Penulisan nama pasien Muhtarom \\
\hline & 29 & & & & $\mathrm{x}$ & & & & & Salah membaca dosis \\
\hline & 30 & & & & & & $\mathrm{x}$ & & & Metronidazol dimasukkan metformin \\
\hline & 31 & & $\mathrm{x}$ & & & & & & & tertulis Cefixim $500 \mathrm{mg}$ \\
\hline & 32 & & $\mathrm{x}$ & & & $\mathrm{x}$ & & & & Bisoprolol ditulis $1 / 2-0$, Bisoprolol XV dimasukkan Bisoproprol 5 XXV \\
\hline & 33 & & & & & & $\mathrm{x}$ & & & Antasid tidak dimasukkan \\
\hline \multirow[t]{3}{*}{ VII } & 34 & & & $\mathrm{x}$ & & & $\mathrm{x}$ & & & Tidak jelas antara amox dan mucylin, signa tidak lengkap \\
\hline & 35 & & $\mathrm{x}$ & $\mathrm{x}$ & & & & & & Metilprednisolon 2×4 mg. Resep lain metilprednisolon 3×8 mg \\
\hline & 36 & & & & $\mathrm{x}$ & $\mathrm{x}$ & & & & Lisinopril $5 \mathrm{mg}$ dimasukkan $10 \mathrm{mg}$, Amlodipine XV dimasukkan XXV \\
\hline
\end{tabular}

